\title{
Conceptual and Empirical Themes regarding the Design of Technology Transfer Programs: A Review of Wood Utilization Research in the United States
}

\author{
Paul V. Ellefson, ${ }^{1}$ Michael A. Kilgore, ${ }^{1}$ Kenneth E. Skog, ${ }^{2}$ and Christopher D. Risbrudt ${ }^{2}$ \\ ${ }^{1}$ Department of Forest Resources, University of Minnesota, St. Paul, MN 55108, USA \\ ${ }^{2}$ Forest Products Laboratory, US Department of Agriculture, Madison, WI 53726, USA
}

Correspondence should be addressed to Paul V. Ellefson, pellefso@umn.edu

Received 7 March 2011; Revised 6 June 2011; Accepted 13 July 2011

Academic Editor: I. B. Vertinsky

Copyright ( 2011 Paul V. Ellefson et al. This is an open access article distributed under the Creative Commons Attribution License, which permits unrestricted use, distribution, and reproduction in any medium, provided the original work is properly cited.

\begin{abstract}
Transfer of technologies produced by research is critical to innovation within all organizations. The intent of this paper is to take stock of the conceptual underpinnings of technology transfer processes as they relate to wood utilization research and to identify conditions that promote the successful transfer of research results. Conceptually, research utilization can be viewed from multiple perspectives, including the haphazard diffusion of knowledge in response to vague and imprecise demands for information, scanning of multiple information sources by individuals and organizations searching for useful scientific knowledge, engagement of third parties to organize research results and communicate them to potential users, and ongoing and active collaboration between researchers and potential users of research. Empirical evidence suggests that various types of programs can promote technology transfer (venture capital, angel investors, business incubators, extension services, tax incentives, and in-house entities), the fundamental effectiveness of which depends on research results that are scientifically valid and consistent with the information needs of potential users. Furthermore, evidence suggests preference toward programs that are appropriately organized and governed, suitably led and creatively administered, and periodically evaluated in accordance with clear standards of success.
\end{abstract}

\section{Introduction}

Research programs focused on wood utilization and product development are an important source of innovation required for sustaining the worldwide competitive position of woodbased industries. In 2008, an estimated 400 to 500 wood utilization research projects were implemented by 150 to 200 federal, state, and private organizations in the United States (US). Total investments in publically sponsored projects ranged from $\$ 110$ to $\$ 120$ million, while, by some estimates, investments in projects sponsored by private concerns exceeded $\$ 2.5$ billion in the same year [1]. A subject for more and more conjecture is the extent to which information generated by such investments promotes increases in the productivity and efficiency of manufacturing processes and product development. In all likelihood, such conjecture arises from the ever-growing scarcity of financial and human resources that are available to public and private research organizations generally [2].
The intent of this paper was to take stock of the conceptual underpinnings of technology transfer initiatives generally and (with aid of experienced research program administrators) to identify programmatic conditions that have been empirically shown to promote the successful transfer of research results. Although the paper focuses on wood utilization research and development in the US, the findings have implications for research management involving a broad range of worldwide geographies and forest resource uses and practices.

\section{Technology Transfer Organizations}

\subsection{Private Program Sponsorship}

2.1.1. Information Transfer Programs. The information needs of individuals and enterprises engaged in the use and manufacture of wood products in the US are often attended to by a variety of private for-profit organizations. In some cases 
the latter investigate (research) important problems posed by clients and convey the resulting information thereto. When doing so, they actively engage in both research and in the transfer of technical knowledge. There are between 20 and 30 for-profit organizations that have assumed such a duel role in the US, of which example mission statements focused on wood utilization are "unlock commercial opportunities in wood fiber and ensure production into new markets and industrial products," "assist clients in the development of emerging polymer technologies and provide timely, costeffective technical support for the application of such technologies," and "for customers, improve the predictability of their paper, paperboard, or converted product through research and its application" [3].

Private for-profit organizations also are known to engage in the transfer of technologies that originate from public and private organizations primarily engaged in research. In the US, more than 1,000 of such organizations focus on technology transfer activities involving wood utilization. Among examples of their interests are "implementing process control systems, instrumentation and energy systems for the paper and composite industries," "application processes involving wood adhesives used in laminated wood and oriented strand board, especially selection, application, and failure of adhesives," and "collection, evaluation and dissemination of information about wood machining equipment and cutting tools as applied to operations such as chipping, sawing, planning [sic], shaping, routing, and sanding" [3].

Myriads of private nonprofit organizations also engage in the transfer of technologies involving wood utilization. In this respect, the number of trade and business associations catering to the technical information needs of their members in the US exceeded 100 in 2006 [3]. Examples of their technology transfer interests are examining and testing materials and processes, developing product and process standards, and lending financial support required in order to implement the findings of research. These interests are often expressed through the publication of technical journals and newsletters and the sponsorship of various educational and training forums.

Wood-based manufacturing companies often engage in wood utilization research and development. In doing so, they actively engage in technology transfer activities focused on company managers and customers. In 2008, 26 companies in the US reported an average investment of $\$ 30$ million (USD) per company ( $\$ 788$ million [USD] total) in research and development or about one-third of the industry's total investments for such purposes ( $\$ 2.4$ billion [USD] in 2006) [4]. Because of company proprietary interests, very little is publicly known about how the information resulting from company-sponsored research makes its way to new product development or to improvements in manufacturing and marketing activities. Publically acknowledged research intentions of companies can provide some insight on wood utilization research and how the products of companysponsored research may be used. Examples of such intentions are "focus on developing new products, improving existing products, and enhancing process technologies to further reduce costs and respond to environmental needs"; "focus on advanced products and new applications to drive future growth"; “... development of manufacturing processes, major process improvements, new product development and design, information technology, and wood related technologies"; "direct research and development activities to short and long-term technical assistance needs ... and to process, equipment and product innovations"; "direct research toward developing new products and processes and improving product performance, often in collaboration with customers" [4].

\subsubsection{Venture Capital Programs}

Venture Capital Firms. Venture capital is a broad subcategory of private equity that refers to equity investments typically made in less mature companies for the launch, early development, or expansion of businesses that seek to transfer the results of wood utilization research into commercially useful wood products and processes. Venture capital firms serve as a means of pooling money from institutional investors and high net-worth individuals, focusing the pooled money on fledgling companies at various stages in research commercialization processes. These stages are seed money (low level financing needed to prove a new idea), start-up money (early stage financing needed to fund expenses associated with marketing and product development), first-round money (funds for early sales and manufacturing), second-round money (working capital for early stage companies that are selling products, but not yet turning a profit), third-round (mezzanine financing) (expansion money for a newly profitable company), and fourth-round money (bridge financing) (money to finance ongoing processes). Fewer than one in 10 entrepreneurs is successful in their requests for venture capital [5]. Venture capitalists select opportunities for investment where there exists evidence that an entrepreneur has [6]

... made some progress in commercializing a new technology and is willing to take on some of the risk associated with the new technology.

... focused on a sector of interest to the venture capital firm (e.g., software development, electronicsinstrumentation, telecommunications, wood and paper products).

... requested funding that is consistent with the financial resources available to the venture capitalist.

... geographic interests and technology commercialization possibilities that are consistent with the geographic parameters of the venture capitalist (local versus national versus global).

... expectations for rates of return that are consistent with rates expected by the capitalist and consistent with the riskiness of attempts to commercialize the new technology.

... an understanding of the role the venture capitalist expects to play in the fledgling company's decisionmaking processes. 
Venture capital deals in the US totaled 2,766 in 2009 (\$6.34 million [USD] average per deal), of which the following sectors were leaders: software-22.3 percent (17.5 percent of funds), biotechnology-14.6 percent (20.1 percent of funds), medical devices and equipment-11.0 percent (14.1 percent of funds), media and entertainment- 9.0 percent (6.6 percent of funds), and industrial energy -8.3 percent (13.1 percent of funds) [7]. Although a finer breakdown of industries within these sectors is not available, the industrial energy sector most likely contains wood-based manufacturing industries (e.g., packaging products, polymer-fiber materials, packaging products, and building products) [6].

Angel Investors. Affluent individuals can also be a source of financing for transforming the results of wood utilization research into commercially viable products and processes. Angel investors are affluent individuals who provide capital from their own funds to a private business owned and operated by someone else who is neither a friend nor a family member. Because they are typically interested in seed startup or early-stage investing (45 percent of total investments), angel investors bear extremely high risk and therefore usually require a very high return on investment - often at least 10 or more times their original investment within five years. Because of such expectations, entrepreneurs interested in commercializing a wood utilization technology developed through research often avoid expensive angel financing for commercialization of a new business [6].

Angel investors operating in the US numbered more than 260,500 in 2008 and provided $\$ 19.2$ billion [USD] in startup funding to 55,480 entrepreneurial ventures involving new technologies. Industry focus for these investments was healthcare (16 percent of investments), software (13 percent), retail (12 percent), biotech (11 percent), industrial energy (8 percent) (major focus on green technologies), and media (7 percent). Although the extent to which angel investors focus on the wood and paper products industry has not been fully determined, the industrial energy and biotech industries would seem to be a likely focus. From 2001 through 2003, the median angel investment for such industries was $\$ 10,000$ (USD) (mean of $\$ 77,000$; range of $\$ 600$ to $\$ 500,000)$ with and average investment return in 2008 of 28 percent. Only a small number of companies who apply get angel investor funding, namely 2.6 percent in 2009 [8].

The characteristics of angel investments provide some insight as to the criterion that are considered when an investment is made in a company promoting a-yet-to-beproven new wood utilization technology. For example, very few companies that receive angel investments have a multimillion-dollar net worth when they receive angel money; angel investors seldom provide follow-up monies to a company; business angels rarely obtain majority ownership of their companies; equity investments made by business angels are often straight common stock purchase; very seldom do angel investors and venture capitalists invest in the same companies; only a small portion of angel investments result in successful businesses that are viable over the long term (are successful) [6].
2.1.3. Business Incubators. Business incubation is a support process that is designed to accelerate the successful development of start-up companies that seek to commercialize the products of research, including wood utilization research. The fundamental intent of business incubators is to produce firms that are viable and freestanding in competitive markets. The common ingredient for all business incubators is "... the opportunity for new ventures to take shelter for, say, two years, from fierce competitive market forces that might otherwise destroy the infant enterprise before it gained size and strength sufficient to compete. This is inherent in the term "incubator" itself" [9].

Business incubators can provide wood-based start-up companies with a wide variety of services and resources, including management guidance, technical assistance, office and manufacturing space, basic business services and equipment, and assistance in obtaining the financial resources considered so necessary to the growth of a new company. Within these broad categories, incubators have been known to sponsor business training programs (accounting-financial management), assist in the development of product marketing plans, provide for linkages to research conducted by institutions of higher education, identify potential advisory board members and management staff, guide fledgling companies through complex regulatory compliance processes, assist in the management of intellectual property, offer access to high-speed internet resources, and inform companies about loans, angel investors, and venture capital. Although most incubators provide office space and shared administrative services to their clients, the "... heart of a true business incubation program is the services it provides to start-up companies that hope to commercialize new technologies developed by research" [10].

Incubation programs come in many shapes and sizes and serve a variety of interests and communities [11] (Figure 1). In 2002, an estimated 3,400 incubators were active worldwide; 1,400 incubators were active in 2006 in North America. In the latter region, incubators reportedly assisted 27,000 companies, provided employment for more than 100,000 workers, and generated annual revenues of $\$ 17$ billion [USD] [10, 12]. Most business incubators in the US are nonprofit organizations (about 94 percent), although a modest number ( 6 percent) are set up to obtain returns on shareholder investments. More than half of all business incubation programs involve "mixed-use" projects, namely, they work with clients from a variety of industries. Among the many industry sectors supported by incubation programs are computer software services, bioscience-life sciences, electronics-microelectronics, telecommunications, medical devices and healthcare technology, advanced materials and composites, energy and clean technologies, and aerospace technologies [10]. The operational dimensions of a business incubator are summarized in Figure 2.

Incubation programs are sponsored by a variety of individuals and organizations in the US In 2006, 31 percent of business incubators in the US were sponsored by economic development organizations with the remaining incubators sponsored by organizations such as state or local governments (21 percent; e.g., Framing our Community 


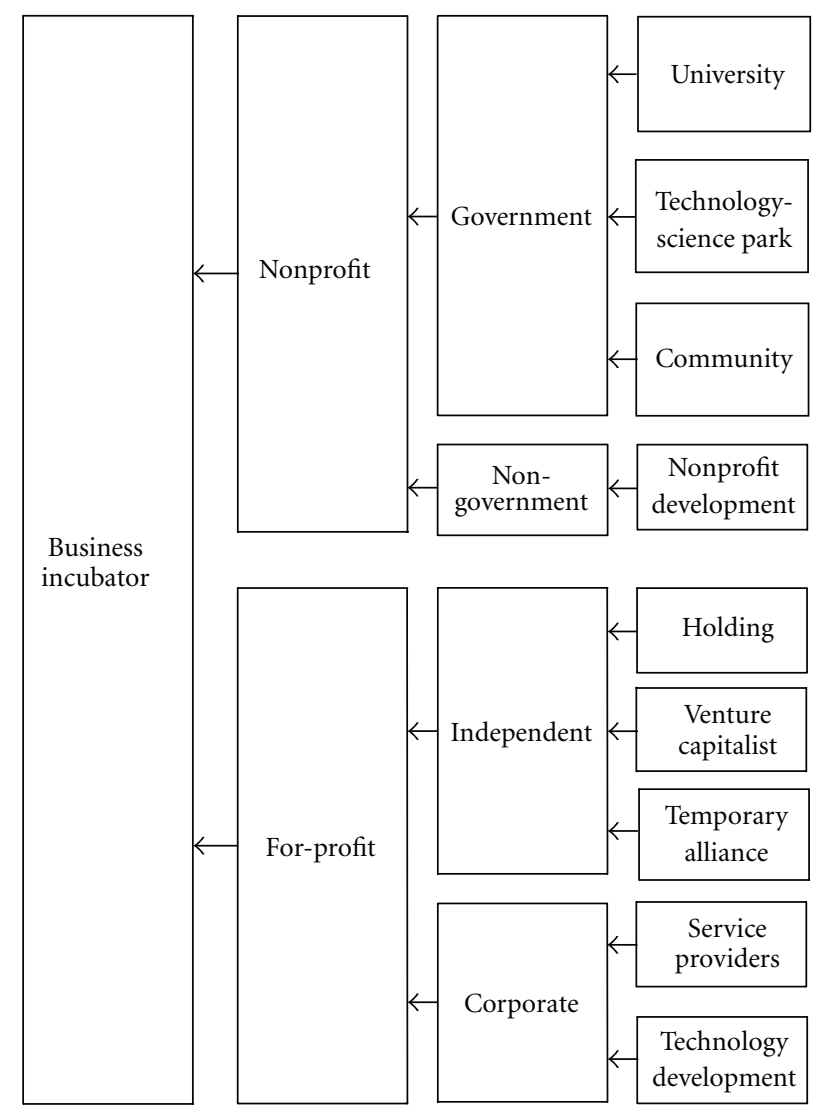

Figure 1: Classification and sponsorship of for-profit and nonprofit business incubators.

Incubator [Elk City Wood Products] [Idaho]), academic and educational institutions (20 percent; e.g., Greenville Wood Composites Incubator [Maine]), and a variety of other sponsors (e.g., US Forest Service, Forest Products Laboratory Incubator [Wisconsin]) [13]. Once established, business incubation programs are encouraged to commit to industry-established best practices, wherein the management and boards of incubators, including wood-based incubators, are encouraged to strive to [14].

(i) Mission: obtain consensus on a mission that defines the wood-based incubator's role in the community and develop a strategic plan containing measurable objectives to achieve the incubator's mission.

(ii) Finances: structure for financial sustainability by developing and implementing a realistic wood utilization business plan.

(iii) Management: recruit and appropriately compensate management capable of achieving the mission of the wood-based incubator and having the ability to help companies grow.

(iv) Governance: build an effective board of directors committed to an incubator's mission and to maximizing management's role in developing successful wood-based companies.

(v) Client Assistance: prioritize management time to place the greatest emphasis on client assistance, including proactive advising and guidance that result in company success and wealth creation.

(vi) Facilities and Resources: develop an incubator facility, resources, methods and tools that contribute to the effective delivery of business assistance to client firms and that address the developmental needs of each wood-based company.

(vii) Community Focus: seek to integrate the wood-based incubator program and activities into the fabric of the community and its broader economic development goals and strategies.

(viii) Stakeholder Support: develop stakeholder support, including a resource network, that helps the incubation program's client companies and supports the incubator's mission and operations.

(ix) Information Management: maintain a management information system and collect statistics and other information necessary for ongoing program evaluation, thus improving the incubator's effectiveness and allowing it to evolve with the needs of wood-based company clients.

The amount of time a potential wood-based company spends in an incubation program can vary widely depending on a number of factors, including the type of business, nature of the technology, and the entrepreneur's level of business 


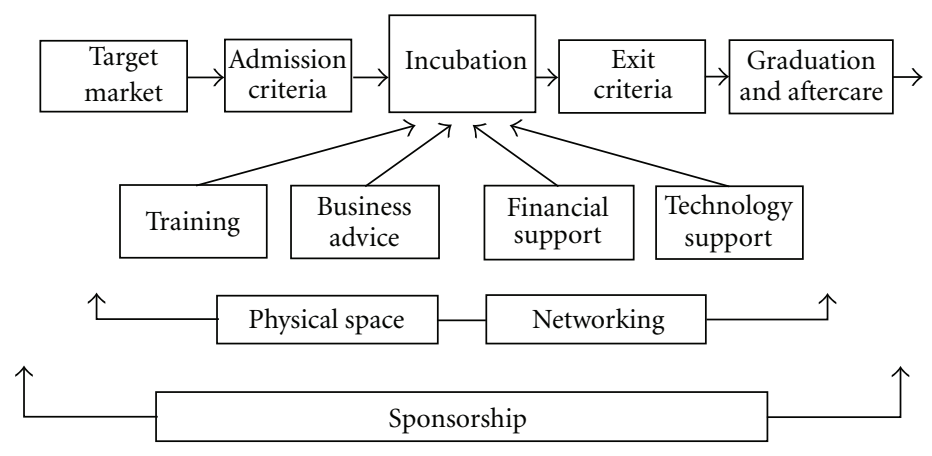

FIgURE 2: Operational dimensions of business incubators.

expertise. On average, members of business incubators spend 33 months in an incubator program. Successful completion of a business incubation program increases the likelihood that a start-up company will stay in business for the long term (historically, 87 percent of incubator graduates stay in business) [10]. In 2007, financial support, links to financial sources, marketing, networking, and protection of intellectual property rights were very important factors influencing success of business incubators [15] (Table 4).

2.2. Public Program Sponsorship. In the US, a variety of state and federal government organizations engage in the transfer of wood utilization technologies developed by research. For some, the commercialization of research-produced technology may be their only and primary mission, while for others technology transfer may be an integral part of a broadly construed research mission. The following are examples of these organizations and programs in the US.

2.2.1. Cooperative Extension Service. Part of the National Institute of Food and Agriculture, the Cooperative Extension Service in the US has historically engaged in extending the results of research through partnerships with land grant universities (about 2,900 extension offices nationwide). Stemming in a major way from authorities granted by the Renewable Resources Extension Act of 1978, in 2007 nearly 50 university extension faculties reported wood utilization and wood products as a focus of their technology transfer efforts (forest-wood products generally-38 persons, harvesting-engineering-11 persons) [16].

2.2.2. Small Business Administration. Charged with assisting and protecting the interests of small businesses generally in the US, including wood-based businesses, the Small Business Administration (within the US Department of Commerce) sponsors the Venture Capital Program-provides venture capital that cannot readily be accessed for reasons of business size, limited assets, or early-stage development of new wood utilization technologies (all sectors: \$1.9 billion [USD] in 2009); Small Business Innovative Research Programs-provides grants for commercialization of new wood utilization technologies that demonstrate a high degree of innovation, have substantial technical merit, and show a good possibility of succeeding in future marketplaces (e.g., wood-based advanced ceramics; structural material from recycled wood fiber) (all sectors: \$1.9 billion [USD] in 2006); the Small Business Technology Transfer Programpromotes partnerships between small wood-based businesses and premier nonprofit research institutions (such as Federal National Laboratories [e.g., Oak Ridge National Laboratory]), the intent of which is to transfer high-tech innovations to the marketplace (e.g., industrial scale alcohol production from renewable feedstocks; matching of renewable energy production with patterns of electrical demand) $[17,18]$.

2.2.3. State Government Incentive Programs. State governments in the US sponsor a wide variety of fiscal and tax incentives programs that have implications for the commercialization of wood-based technologies developed by research. Although the majority of these programs are focused on state interests in economic development generally, many are designed to directly enhance the investment climate for the commercialization of new technologies resulting from research. State tax credits focused on angel investors are an example, the purpose of which is to reduce the risk and cost of angel investing in order to encourage more entrepreneurial activity in high-growth small businesses that seek to commercialize newly developed wood utilization technologies. Depending on the state, the income tax credits range from 10 percent to 100 percent (averaging 35 percent for 20 states). Some modest few states also sponsor venture capital funds and offer centralized incubator funding (e.g., the state of Michigan's Pre-Seed Capital Fund supports hightech start-up companies as they near commercial viability) $[19,20]$.

2.2.4. Federal Research and Development Programs. Federal research organizations actively engage in efforts to transfer the products of their research to various users. For example, within the Forest Service's (within the US Department of Agriculture) Forest Product Laboratory the Technology Marketing Unit has special responsibility for the transfer of research-produced technology involving wood utilization and marketing (employed four technology transfer specialists in 2010). The Unit's mission is to “... promote 
the efficient, sustainable use of wood by transferring technologies developed by the Laboratory and certain other research entities." The Unit's programs are expressed in various forms, including publications, technical assistance visits, conferences, workshops, demonstration projects, and face-to-face advice to potential users of new wood product and process technologies [3].

Federal National Laboratories (within the Office of Science, US Department of Energy) in the US also engage in research, nine (total of 17) of which engage in wood utilization and development research (e.g., various divisions of materials science; centers for nanotechnology, centers for bioenergy, divisions of renewable energy). These Laboratories have very active technology transfer programs that seek to (e.g., Argonne National Laboratory) “... pro actively deliver advanced technology and unique technical services to industry by targeting strategic emerging highimpact technologies and forming market-driven alliances ... and to expand benefits to users of technology, enhance market impact, and contribute to solution of important domestic problems." These objectives are accomplished via licensing agreements, cooperative research and development agreements, personnel exchange programs, research and development consortia, technical assistance to small business, and user facility agreements. Staffed with 10 to 12 persons per entity, the entities within National Laboratories that administer technology transfer programs are clearly labeled as such (e.g., Office of Technology Transfer, Office of Technology Transfer and Commercialization, and Office of Technology Commercialization and Partnerships). In all cases, offices of technology transfer report directly to the director of a National Laboratory and are equal in rank to a Laboratory's scientific divisions [20].

2.2.5. Universities and Colleges. Universities in the US are major sponsors of technology transfer programs, motivated by their interest in teaching, generating new knowledge, and being of service to society. Most technology transfer programs of universities seek to generate revenue and institutional recognition, preserve intellectual property rights, facilitate cooperation and formal partnerships, and protect academic research enterprises as a source of future innovations. An example mission statement (North Carolina State University) is to "... protect and promote the discoveries of researchers ... doing so by protecting university intellectual property ... commercializing new technologies ... supporting startup companies ... providing training and education ... and marketing intellectual property." In the US, all 26 universities that have wood science and technology research and education programs accredited by the Society of Wood Science and Technology (2010) have university-wide centers, offices, or foundations focused on technology transfer [21] (Table 1). An average of 11 persons (professional and support) is assigned to each entity, most often including a director, licensing and patenting specialists, and a variety of managers responsible for specific areas of technology (e.g., engineering, life sciences, health sciences).

Universities in some cases have chosen to promote technology transfer through a separate foundation (e.g., Virginia
Polytechnic Institute and State University's Virginia Tech Intellectual Properties, and the University of Wisconsin's WiSys Technology Foundation, Inc.). Some universities in the US are very active participants in the development of commercial business ventures based on technologies developed by university researchers (e.g., the Oregon State University Venture Capital Fund [commercializing the application of a new wood adhesive made from renewable materials] and the University of Washington's Technology Gap Innovation Fund). Others express an interest in startup companies by offering to take a small equity stake in such companies in lieu of upfront fees and for the deferral of patent reimbursements (e.g., University of Idaho), while a number of other universities provide start-up companies an opportunity to participate in heavily subsidized facilities at university-owned research parks (e.g., Auburn University's Auburn Research Park).

\section{Conceptual Perspectives}

Evaluating the extent to which knowledge provided by research is utilized presumes a conceptual basis or model for doing so. Commonly accepted over the years have been various linear interpretations of knowledge utilization, namely, "one does research, research leads to development, development leads to production, and production to marketing," a conceptual framework that many suggest misrepresents innovation processes as a series of smooth, well-behaved linear events, ignorant of the many complex causal factors that are at work [7, 22-24]. Woefully inadequate in the minds of many is the lack of rigorous and widely agreedto conceptual frameworks that can guide the evaluation of knowledge utilization, for example, “... there is not yet an integrated conceptual model of research utilization ... little is known about the factors that induce professionals and managers to use research in their professional activities" [13], "... much of the ambiguity in the discussion of research utilization derives from conceptual confusion" [24], and “... despite several attempts to development conceptual models for explaining the use of research, there is not yet an integrated conceptual model for use by experts in the field of knowledge utilization" [25]. Adding to the challenge of evaluating the utilization of research is the often poorly defined terminology suggested as valid measures of knowledge utilization (when is "information diffused," "knowledge utilized," and "research implemented?"). As described below, technology transfer has been conceptualized in three major ways, namely the science-knowledge environment generally, utilization of knowledge by individuals, and utilization of knowledge by organizations.

3.1. Universal Utilization of Knowledge. Set forth in an allinclusive fashion, the relationship of research and the use of products therefrom have been suggested as an environment of free-flowing and unbridled research that seeks to expand understanding of human and natural worlds generally, to models asserting the importance of linkages between researchers and the persons and organizations that have a direct interest in the products of investments in research. 
TABLE 1: Technology transfer entities at universities with wood science and technology programs in the United States, by university and number of staff. 2010.

\begin{tabular}{|c|c|}
\hline University & Technology transfer-commercialization office \\
\hline Auburn University & Office of Technology Transfer (9) \\
\hline Clemson University & Office of Technology Transfer and Business Innovation (4) \\
\hline Iowa State University & Office of Intellectual Property and Technology Transfer (15) \\
\hline Louisiana State University & Office of Intellectual Property, Commercialization and Development (NA) \\
\hline Michigan State University & MSU Technologies (18) \\
\hline Michigan Technological University & Technology and Economic Development (8) \\
\hline Mississippi State University & Office of Technology Commercialization (5) \\
\hline North Carolina State University & Office of Technology Transfer (14) \\
\hline Oregon State University & Office of Technology Transfer (five) \\
\hline Pennsylvania State University & Intellectual Property Office (12) \\
\hline Purdue University & Office of Technology Commercialization (8) \\
\hline Southern Illinois University & Technology Transfer Program (2) \\
\hline State University of New York at Syracuse & Office of Technology Transfer (6) \\
\hline University of Georgia & Technology Commercialization Office (10) \\
\hline University of Idaho & Office of Technology Transfer (5) \\
\hline University of Kentucky & Office of Commercialization and Economic Development (28) \\
\hline University of Maine & Office of Research and Economic Development (6) \\
\hline University of Massachusetts & Office of Commercial Ventures and Intellectual Property (6) \\
\hline University of Minnesota & Office of Technology Commercialization (36) \\
\hline University of Tennessee & UT Research Foundation (9) \\
\hline University of Washington & Center for Commercialization (47) \\
\hline University of Wisconsin - Madison & Wisconsin Alumni Research Foundation, Inc. (NA) \\
\hline University of Wisconsin - Stevens Point & WiSystem Technology Foundation, Inc. (5) \\
\hline Virginia Polytechnic Institute \& State University & VA Tech Intellectual Property (8) \\
\hline Washington State University & WSU Research Foundation (9) \\
\hline West Virginia University & Office of Technology Transfer (7) \\
\hline
\end{tabular}

Note: number in parentheses is number of staff persons in a technology transfer unit.

Source: Reference [21], and individual university web sites.

Although such diversity is acknowledged, the literature suggests four major conceptual frameworks for assessing this continuum $[7,13,24,26]$ (Table 2). First, general diffusion of scientific knowledge, where researchers define and conduct research, the results of which advance in an uncertain fashion to various users (research is viewed as part of the intellectual enterprise of society generally). Information transfer is not automatic and is seldom guided by any single entity. Second, imprecise demand for knowledge wherein the demand for the products of research is ill defined, and the cultural differences between users and researchers are significant. In such an environment, individuals and organizations scan the landscape for useful information but have very limited influence over the focus of research (products of research are conveyed in forms understood by researchers but which are confusing to users). Third, facilitated interaction as a concep- tual framework advances the importance of collaboration, interpretation, and dissemination activities in which third parties become the interface between users and researchers. Their role is one of enabling a better research focus on userdefined problems and on the subsequent use of products produced by researchers. And fourth, suggested as a research utilization framework is direct user-researcher interaction, which suggests the importance of personal contacts in defining problems in need of research, ways of conducting research, and avenues for utilizing the findings of research.

The aforementioned frameworks have a number of implications for the utilization of knowledge produced by research involving wood utilization. For example, unbridled generation of scientific information by researchers is no guarantee that the products of wood utilization research will be transferred to potential users nor that the knowledge so 
TABle 2: Conceptual frameworks for research and scientific investigations, by key attributes and implications for research utilization and technology transfer.

\begin{tabular}{lll}
\hline Research framework & Key attributes & Implications for research utilization \\
\hline $\begin{array}{ll}\text { (A) Diffusion of } \\
\text { scientific knowledge }\end{array}$ & $\begin{array}{l}\text { (i) Researchers are the source of ideas for research and } \\
\text { for conducting research. }\end{array}$ & $\begin{array}{l}\text { (i) Interaction between researchers and users of } \\
\text { research products is virtually nonexistent. }\end{array}$ \\
& $\begin{array}{ll}\text { (ii) Users of research products are poorly defined (if at } \\
\text { all). }\end{array}$ & $\begin{array}{l}\text { (ii) Transfer of knowledge is not assured and certainly } \\
\text { not automatic. }\end{array}$ \\
& $\begin{array}{ll}\text { (iii) Research products advance aimlessly from } \\
\text { researchers to users (nonlinear). }\end{array}$ & (iii) Responsibility for transfer of knowledge is not \\
& & assigned to an individual or organization. \\
& (iv) Raw and unformatted knowledge is not always \\
\end{tabular}

\begin{tabular}{ll}
\hline (B) Imprecise & (i) Users of research are sources of ideas for research, \\
demand for & although most times in a very limited and indirect \\
knowledge & manner.
\end{tabular}

(ii) Researchers and users have markedly different cultures which restrict communication.

(iii) Research products advance sporadically and inconsistently from researchers to potential users.

(C) Facilitated interaction for knowledge products is limited, although facilitated by third parties. (i) Interface between researchers and users of research

(ii) Problems are identified, defined and made known to researchers by third parties.

(iii) Useful products of research are identified, configured, and presented in useful forms to users by third parties.

(D) Direct user-producer interaction for knowledge (i) Interaction between researchers and users of research products exists at all stages of knowledge production.

(ii) Researchers actively seek user advice on problem definition, research approach, and ways of facilitating the use of research products. (i) Research focus is often ill-defined and unclear, thus making research products of limited use.

(ii) Cultural differences limit interaction between researchers and users of research products.

(iii) Limited interaction between researchers and users limits utilization of research products.

(i) Researchers and users of research products are neither involved in the selection of researchable problems nor the selection of transferable information.

(ii) Third party interlocutors may be limited in ability to bridge the user-researcher interface. (i) Instrumental role of research is focused on at expense of unfettered freedom to research unexplored subjects.

(ii) Access to the products of research is limited to few users of the products of research.

(iii) Very technical and very narrow products of research limit their broader application.

(iv) User organizational interests (limited time for research, change in problem definition, proprietary considerations) can compromise the integrity of research processes and products.

Source: adapted from [26].

generated will be of value to clients of research. Similarly, poorly defined research objectives can lead to research products that fail to adequately address the important information needs of users or that are delivered to users in ways and forms that make the products of wood utilization research unusable. As for facilitated user-researcher interactions, the imposition of a third party may do little to bring users and researchers together in manners that truly focus on information needs. Third-party interlocutors that are poorly informed can do little to bridge the user-researcher interface. As for direct user-producer interaction, researchers engaged in wood utilization research can become captive to the narrow interests of users and thereby lose their freedom to more broadly explore problems and research approaches that may have greater payoffs for more efficient utilization of wood.

3.2. Individual Utilization of Knowledge. The manner in which individuals respond to the products of research has also been suggested as a conceptual foundation for technology transfer. From such a perspective, user response to a product of research is not viewed as a single discrete event, rather it is considered to be a spectrum of decisions that may (or may not) lead to the application of information provided by research. At any point in the decision process, the products of research can be derailed-regardless of 
their virtue [23]. Suggested is that individuals engage in the following stages of knowledge utilization [13, 23, 24, 26, 27].

(i) Received: "I received research-produced information that is pertinent to my work."

(ii) Understood: "I read and understood the information that was received."

(iii) Referenced: "I cited the information as a reference in my own documents or reports."

(iv) Adapted: "I adapted the format of the information so it was useful to others."

(v) Promoted: "I made efforts to promote the research evidence at meetings and similar venues."

(vi) Influenced: "I made choices I would not have otherwise made, based on the research information."

(vii) Applied: "The information provided by research lead to concrete changes in the operation of my unit."

A major implication of this conceptual approach to wood utilization research is the narrow focus on a single person. In reality, decisions to use knowledge are greatly influenced by collaborative actions of managers and the culture and mission of the organizations of which they are a part [23, 26]. Furthermore, the approach does not help explain how individuals respond to conditions in which the results of wood utilization research are in conflict.

3.3. Organizational Utilization of Knowledge. The ability of organizations to assimilate the products of research has also been offered as a conceptual basis for technology transfer. The hallmark of an organization that has effective research utilization capabilities is typically one that has made knowledge absorbing processes part of normal organizational routines (e.g., training, conferences, internet access). Viewed as a process, suggested is that an organization's capacity to absorb knowledge involves four major steps [23, 26, 28].

(i) Acquisition: capacity to scan external landscapes and to subsequently identify and acquire external knowledge that is critical to an organization's operations.

(ii) Assimilation: capacity to analyze, interpret and understand knowledge acquired from external sources.

(iii) Transformation: capacity to combine newly acquired knowledge with already assimilated knowledge.

(iv) Exploitation: capacity to use and take advantage of new knowledge by developing new capabilities that improve an organization's operations.

Although such a framework has merits for understanding the use of knowledge produced by wood utilization research, the bridge between an individual manager's reliance on the products of research and the innovative character of an organization generally has been subject to much conjecture. Argued is that the relationship between individual and organizational learning involving the products of research is far from clear-organizational learning goes beyond the simple accumulation of individual learning that is grounded in research [26].

\section{Technology Transfer Determinants}

Conditions that determine whether the products of wood utilization research will be utilized have been suggested by a number of analyses and by considerable speculation and conjecture. They range from the importance of close working relationships between researchers and potential users of research, to the necessity for timely introduction of research into decision making processes, and from the significance of sound scientific and analytic footings for research, to the importance of having the results of research presented in understandable and appealing formats. From the perspective of wood utilization research, these and related conditions can best be appreciated if grouped into five major summary categories as follows [26, 29].

(i) Type and Content of Research. Are the products of wood utilization research scientifically and analytically trustworthy? Are they presented in formats that suggest they are quantitatively valid (arise from scientific and analytic rigor); qualitatively logical (arise from reasoned principles and objective examples); scholarly motivated (arise from scholarly and scientific interests); uncertain or questionable (arise from speculation and conjecture)?

(ii) Organizational Context. Are the products of wood utilization research cognizant of managerial conditions within an organization? Are they relevant to unique problems faced by a specific organization; properly timed and eagerly sought by managers; complementary to the mission, policies, and programs of an organization; directed at an organization's proper managerial level and geographic entity; relevant to the size (small versus a large entity) and geographic scope (national versus international) of an organization?

(iii) Culture of Users-Researchers. Are the products of wood utilization research reflective of common user-researcher interests? Are they easy for users to understand, appealing in format, operationally specific, and clinically verifiable; reflective of user-researcher mutual appreciation for management of organizations (operational performance, decisive decision-making) and for the conduct of research (scientific methods, analytical rigor)?

(iv) User-Researcher Linkages. Are the products of wood utilization research emanating from a healthy consultative relationship between users and researchers? Are they products of intense user and researcher interaction at all stages of knowledge utilization (problem definition, research design, application of findings); reflective of users and researchers having interacted via a wide variety of formal and informal communication channels (one-on-one meetings, informal gatherings, formal conferences-seminars, electronic mail, libraries, and data banks)?

(v) User and Manager Attributes. Are the products of wood utilization research the result of engagement of reliable and qualified participants? Are they products of scientific 
TABLE 3: Users perspectives on the conditions constraining the use of information provided by forestry research.

Constraint on use of research

-Unaware of new technology or innovation

-Sources of new technology or innovation lack credibility

-Poor fit for new technology or innovation

-Inadequate understanding of new

technology or innovation

-Unaware of problem requiring application

of new technology or innovation

-Inappropriate timing for application of

new technology or innovation

-Lack of enabling conditions or incentives to use new technology or innovation

Source: adapted from [29].
User perspective on cause of constraint

-Poor dissemination of research results, inadequate user involvement in research processes, and large supply of competing or contradictory information.

-Lack of influential partners or clients, lack of familiarity with producers of research, uncertain credibility of technology's science, and research findings contrary to conventional wisdom.

-Research results address a low-priority problem, technology inflexible or difficult to adapt, inappropriate format-presentation of research results, and lack of user involvement in development of new technology.

-Unclear purposes or possible application of new technology, insufficient capacity of user to use new technology, and poor format and presentation of new technology.

-Lack of information about a problem requiring new technology, lack of capacity to diagnose a problem in need of new technology, and problem disregarded by user.

-Technology available but conflicts with conventional wisdom, limited window of opportunity for using new technology.

-Lack of capacity to implement new technology, inadequate incentives to adopt new technology. inquiry carried out by knowledgeable and understanding scientists and scientific organizations; consistent with the abilities (experience, education) of organizational managers to assimilate and make use of the products of research?

The style and background of managers and professionals have also been suggested as major factors determining the extent to which wood utilization research is favorably received. In this respect, variables likely to explain the use of wood utilization research are a manager's (a) ability and willingness to learn, (b) past experiences in research leadership positions, (c) allotment of time to research entities and endeavors, (d) level of formal education attained, and (e) perception of how relevant the results of research are to an organization's operations. In addition to such indicators, other measures are attitude toward the products of research (manager's preferred source of information), intensity of use of research products (manager applied research products in the past), linkage between users and researchers (manager actively engaged with researchers in the design of research), access to the results of research (manager attends demonstrations of how to use research results), and past experiences with research practices and processes (manager having collected research data in the past). Evidence suggests that an organization's ability to acquire, react to, and incorporate the products of wood utilization research into decision making processes is heavily dependent on managerial and professional characteristics such as these [26].

The context within which managers operate can also affect the use of information provided by research. If the results of wood utilization research are suggesting that "something different needs to be done," managers are likely to ask questions such as the following: relative advantageis the innovation better than what it replaces and are additional costs outweighed by the benefits? Compatibilitydoes the innovation fit with current practices, norms, and values? Complexity - is it simple to understand and easy use? Trialability — can the innovation be tested on a trial basis without large upfront investments? Observability - are the benefits readily discernable? And, reversibility - is it possible to stop using the innovation and to continue as before? From a manager's perspective, constraints on the use of wood utilization research can be daunting, ranging from contradictory results of research to inappropriate timing for its application and from unclear purposes of the new technology to inadequate incentives for its application $[29,30]$ (Table 3).

Manufacturing establishments can be major users of new technologies brought forth by research. Conditions at play when wood-based company decisions are made to use (or not use) research range from how well the products of wood utilization research advance a company's mission and competitive position, to whether a company has an established process for identifying and examining new technologies, and from the effectiveness of information management systems internally available to a company, to the willingness of company managers to actively and willingly express visible support for new technologies [31-34]. In a more focused sense, determinants of research utilization within a woodbased manufacturing environment may well be consistent with empirical evidence from manufacturing generally as follows (identified from nearly 30 references on research diffusion amassed by Boyle [31]). 
TABLE 4: Factors influencing the success of public and private business incubators, by ranked importance of factor. 2007 .

\begin{tabular}{lcc}
\hline Factor & $\begin{array}{c}\text { Public } \\
\text { incubators }\end{array}$ & $\begin{array}{c}\text { Private } \\
\text { incubators }\end{array}$ \\
\hline Financial support & 1 & 1 \\
Links to financial resources & 2 & 6 \\
Marketing & 3 & 5 \\
Networking with strategic partners & 4 & 2 \\
International collaborators & 5 & 4 \\
Intellectual property rights protection & 6 & 3 \\
Legal counseling & 7 & 7 \\
Strategic counseling & 8 & 7 \\
Market information & 9 & 8 \\
Access to labor pool & 10 & 13 \\
Management support & 11 & 11 \\
Networking of facilities & 12 & 9 \\
Source of technological information & 13 & 14 \\
Professional network & 14 & 10 \\
Advanced training and studies & 14 & 15 \\
Connections with suppliers & 15 & 16 \\
Available suitable space & 16 & 12 \\
Access to inputs & 17 & 16 \\
\hline
\end{tabular}

Note: 1 = highest importance, 17 = lowest importance.

Source: adapted from [15].

(i) Context Oriented Factors (Wood-Based Company Mission, Structure and Culture Favor Research and the Products Therefrom). New technology is important to company mission and strategic interests; company has a history of receptivity to new ideas and technologies; adopting new technology poses acceptable risk and liability to company; initial and ongoing financial requirements posed by new technology are acceptable; new technology is applicable and expected to persist for an acceptable period of time; company size and structure complement adoption of new technology (small versus large organization, formalized and centralized versus decentralized and flexible); and programs for training and educating employees about new technology are available to a company.

(ii) Process Oriented Factors (Wood-Based Company Processes for Converting Products of Research into New Processes or Products are Available). Administrative layers between company researchers and managers are few; group sessions to promote creative discussion of visions and barriers to the adoption of new technologies can be readily exercised; opportunity exists to collect pro-con views from disparate entities within a company; technical requirements of existing processes and products can easily be transformed to meet the requirements of the new technology; opportunity exists for many sequential rounds in which company researchers and managers can offer opinions and visions regarding the new technology; prototypes making use of the new technologies can be promptly developed and observed; ability to target new technology to selected sets of potential adopters exists within a company.

(iii) People Focused Factors (Wood-Based Company Researchers and Managers Actively Engage in Research and in the Conversion of Research Products into New Products and Processes). Company managers are receptive to new technologies and are willing to actively and willingly express visible support for suitable technologies; company researchersmanagers are located in one physical location; information management technologies stimulating communication and information sharing occur widely within a company; new product development engages the knowledge of customers, managers, suppliers, and researchers; evaluation and reward for new process and product development are focused group wide within a company; researchers and managers are willing to refine, elaborate, and modify products of research; company managers view the new technology as easy to understand and use and view the technology as better than technologies to be superceded (relative advantage); demographics of company employees suggest adoption of the products of research (age, gender, education); the number of company employees that will be required to change behavior and work patterns is acceptable.

(iv) Information Focused Factors (Wood-Based Company Information Management Systems Facilitate Research and the Adoption of Products Therefrom). Company can offer a single database for storage of information concerning new process and product development; reliable software exists to simulate the impact of new technologies on company manufacturing processes and new products.

\section{Technology Transfer Program Design}

The efficiency and effectiveness of technology transfer programs are in large measure determined by how well they are designed and administered. Since the intent of this paper was to take stock of conceptual and empirical findings regarding the transfer of technologies provided by wood utilization research, consideration must also be given to current evidence regarding program design and administration. Although the bulk of the information previously presented provides substantial guidance in this respect, useful insights can also be gained from program administrators engaged in the commercialization of wood utilization research as well as the technology transfer experiences of those operating in non-wood-based research sectors.

5.1. Administrator Perspectives. Experienced administrators can be an important source from which we draw ideas for the design of technology transfer programs. In 2006 and 2009, more than 50 executive-level administrators (of which 30 responded) of wood utilization research programs and technology transfer programs located in the US and in 23 other countries were asked the following question: "if they are to be used, the products of wood utilization research require a well-organized, skillfully managed and 
carefully monitored set of technology transfer activities. What organizational, managerial and performance assessing features of your organization enable it to effectively convey newly developed technologies to users?" The following summarizes the most common themes contained in the administrators' responses $[3,35]$.

(i) Organization and Governance (Are Administrative Structures Available to Facilitate Transfer of Wood Utilization Technology?) Organization's overall mission emphasizes and promotes technology transfer; administrative entities (e.g., bureaus, divisions) exist for facilitating technology transfer activities; governance structures (e.g., boards, advisory committees) established for guiding research programs toward technology transfer and the information needs of clients; cooperative structures (e.g., partnerships, incubators) established for facilitating the commercialization of newly developed technologies.

(ii) Administration and Management (Is the Process of Transferring New Wood Utilization Technologies Well Managed?) Blend of research programs and technology transfer initiatives is seamless; executives and research program managers emphasize and promote transfer and commercialization of new technologies; communication between research enterprises generally and groups of users (e.g., industrial associations) is sizeable and wide ranging; broad range of different types of technology transfer strategies and programs are put to use; talented researchers are actively engaged with clients and vice versa; objectives of research and the new technologies resulting therefrom are suitably explained to clients; worthiness to users of potential products resulting from research is assessed in advance; suitable numbers of talented and resourceful specialists are assigned to entities responsible for facilitating the transfer of technologies; researchers and research enterprises are committed to longlasting relationships with clients; scientifically credible and well-timed research is provided to users; research enterprises partner with other entities to cooperatively promote effective transfer of new technologies, and the confidentiality of certain types of client-provided information is respected.

(iii) Performance and Success (Are Processes and Programs for Transferring Wood Utilization Technology Effective?) Administrators and researchers welcome and respond to periodic evaluation of technology transfer initiatives; administrative structures (e.g., policy centers, evaluation institutes) exist to facilitate periodic assessment of technology transfer activities; standards for measuring success are relevant and measurable (e.g., innovative products and processes, additional revenue and profit, repeat requests for research services); technology transfer is viewed as important to the financial health and reputation of research enterprises; products of research are relevant to clients' needs and are presented in a user-friendly fashion; users actively and willingly seek new technologies and support research programs in general.
5.2. Multisector Perspectives. The experience of research administrators operating in non-wood-based sectors can also offer important attributes of technology transfer programs. Often suggested is that the latter are useful to the extent they transfer products of wood utilization research that are scientifically and analytically sound, transmit knowledge from credible and reliable research organizations, provide information relevant to conditions faced by managers and administrators (focused, timely, pertinent), seek to present information in forms consistent with the abilities and needs of users (easy to understand, appealing in format, operationally specific, clinically verifiable), and depend on research environments which promote close and active user-researcher working relationships [26]. As an example relevant to the transfer of wood utilization research, administrators of programs successfully transferring environmental technologies suggest that programs should [36]

(i) address critical information needs of potential users (who are the users and what information do they need?);

(ii) accommodate the competencies of potential users (do potential users have the expertise to understand a new technology and, if not, how might they be made appreciative of it?);

(iii) respect uncertainties and risk aversion of potential users (do potential users consider the new technology a sizeable risk and, if so, how might riskiness be reduced or users made more adventuresome?);

(iv) respect motives of potential users (do potential users face financial hardship if a new technology is adopted and, if so, how might financial and market-driven constraints be eased?);

(v) utilize information formats well situated to potential users (do potential users dislike [do not understand] certain technology transfer formats [e.g., academic journals] and, if so, how might information be reformatted?);

(vi) recognize time horizons needed for adoption by potential users (do potential users understand the often long time periods for successful adoption of new technologies and, if not, how might planning horizons be made more accommodating to longer term payoffs?);

(vii) favor flexible and opportunistic schedules consistent with the agendas of potential users (do potential users fear standardized schedules for utilizing new technologies and, if so, how might adoption schedules be made more flexible?);

(viii) make use of a broad set of implementation tools (do potential users respond better to a broad range of technology transfer approaches [pilot projects, scientists on-sight]?).

Transfer of research-produced technologies has also been found to be greatly facilitated by partnerships between and within public and private organizations. To do so, administrators suggest that they must be properly constructed, 
operated, and evaluated, namely, have clear objectives, measurable outcomes, well-defined responsibilities, appropriate sharing of costs, and timely evaluation of effectiveness. The reality that partnerships are usually temporary entities tends to ensure early recourse to private investments and possibly a more rapid commercialization of new wood utilization technologies [22, 37-39].

5.3. Company Perspectives. Private companies, including wood-based companies, often have in-house research programs that engage in the transfer of new technologies. To be effective, evidence gathered from company research administrators suggest they must be designed to provide information that advances a company's competitive position and must be fully integrated into company processes used to identify and examine new technologies generally (e.g., information management systems). Especially important to the assimilation of new technologies are company managers that appreciate the value of technical advances in general and who willingly advocate the importance of technology transfer initiatives in general $[33,34]$.

Technical advances developed beyond the internal workings of private companies are also considered important by research program administrators. From a program design perspective, the latter suggest that there is much virtue in the existence of a seamless weave of internally and externally available research and innovation services. By establishing a web of such linkages, companies become better positioned to coinnovate with customers (innovate solutions to new problems), spread the consequences of high-risk innovations (joint ventures, equity partnerships), and expand research productivity by accessing innovative talent across sectors and national and international boundaries (partnerships between scientists and engineers). Private sector interest in partnering with universities (research consortia, grants, and contracts), cooperating with federal laboratories (research and development contracts) and participating in formal alliances and joint ventures with other companies has grown significantly in recent years. Especially rewarding to company research administrators are collaborations involving companies and universities, especially in the field of advanced materials (e.g., coated materials, antibacterial materials), including wood-based materials [38, 40-42].

The design of programs for the transfer of new technologies from public research organizations to private companies requires a mutual understanding of the technology to be transferred and the ability (capacity) of companies to effectively act on the new technology. From a program design context, administrators suggest that this interdependence requires an understanding of factors such as the following $[33,34,43]$.

(i) Technical factors: Does the company ... understand the new wood utilization technology, have access to necessary facilities and equipment, have access to technical and engineering skills, and have the capability of making design changes in the new technology that are necessary to achieve commercialization? (ii) Business factors: Does the company ... have a mission and goals that are consistent with the new wood utilization technology, demonstrate strength in the area of the new technology, have a clearly defined set of existing and potential customers, properly characterize the market size and chances of successful access, have a competitive advantage in the marketplace, have a well-developed inquiry to commercialization, demonstrate manufacturing and marketing capabilities, and have appropriate financial and personnel resources?

(iii) Management factors: Does the company ... have commitment of leadership and management to new wood utilization technology, well-defined project management and scheduling skills, demonstrate reasonableness of proposed time lines and required resources, exhibit past management team strengths and capabilities, and have a record of successful commercialization of new technologies?

(iv) Economic impact: Does company ... have commercialization plans for the new wood utilization technology that will lead to financial and organizational benefits to the company, new high-quality jobs, positive impact on consumers and taxpayers, commercialization impacts in reasonable time periods, potential export of new processes and products, and positive impacts on company's local community?

\section{Summary and Future Investigations}

The transfer of new technologies produced by research is critical to innovation within all public and private entities that utilize wood. With a focus on the latter, the intent of this paper was to take stock of the conceptual underpinnings of technology transfer initiatives generally and to identify programmatic conditions that have been empirically shown to promote the successful transfer of research results. The importance of research to innovation within the world's wood-based manufacturing sector gives credence to the importance of the paper.

6.1. Summary. Conceptual frameworks explaining the diffusion of research-produced knowledge have yet to be fully developed. However, provisional frameworks suggest that knowledge transfer can involve chaotic and haphazard diffusion of knowledge (researchers define and conduct research, the results of which find their way in an uncertain fashion to possible users); individuals and organizations scanning - in an orderly fashion - the landscape for useful information produced by nameless researchers (users have limited influence over the focus of research and are culturally detached from researchers); user-researcher interaction facilitated by a third party (detached third parties promote the collaborative movement of information between users and researchers); direct and active involvement of users and researchers focused on defining information requirements and how such information will be applied (and by whom). 
Conditions prompting users to apply the technologies provided by research entities are wide ranging, although experience suggests the importance of the validity of the research products (e.g., embody scientific and analytic rigor), consistency of research with organizational needs (e.g., properly timed and complementary with mission), friendliness of research to potential users (e.g., presented in understandable and appealing formats), extent of user-researcher interaction during research processes (e.g., agreement on a clear definition of the problem), and compatibility of research with user responsibilities (e.g., directed at proper management and geographic level). Especially rich sources of information about technology transfer conditions are experienced managers of research and technology transfer programs. The review contacted 30 such persons in 40 different countries. In sum, they pointed to the importance of technology transfer programs that are properly organized and governed, suitably led and creatively administered, and periodically evaluated in accordance with clear standards of success. From an organizational perspective, the administrators advise that these desirable conditions can be incorporated within various types of programs, including venture capital programs, angel investors, business incubators, extension services, tax incentives, and in-house entities.

6.2. Future Investigations. How and under what circumstances the products of research influence managerial decisions that are ultimately transferred into useable products and processes have received only modest attention in recent years, a condition that is not unique to wood utilization research or forestry research generally. Given the magnitude of public and private investment in research and the likelihood that research investments in the near future will grow only modestly, technology transfer processes deserve attention. In addition to presenting an introduction to current thinking on the transfer of new technologies developed by research, this paper identified-in discerning, yet critical fashion-a number of voids in the literature as they involve research utilization. In the spirit of encouraging future analysis toward especially noteworthy technology transfer issues, the literature appears to be lacking in attention directed to the following broad subject areas.

(i) Developing A Better Conceptual Framework for Explaining Technology Transfer and for Guiding the Subsequent Design and Implementation of Technology Transfer Programs. Conceptual frameworks for explaining technology transfer are frequently cited in the literature as inadequate. What fundamental concepts should be embodied in models that might serve as logical and fully integrated touchstones for explaining the utilization of research? Should such models have a universal orientation, organizational orientation, individual user orientation, or some combination thereof? And what terminology would serve best to universally describe the processes that are embodied in legitimate technology transfer models?

(ii) Formulating A Fundamental Understanding of Conditions Determining Whether the Products of Research are Utilized.
Conditions that induce professionals and managers to use the products of research are frequently cited in the literature as not being fully understood. To be assessed within a solid conceptual framework, what factors promote the transfer of new technologies developed by research (e.g., scientifically trustworthy information, timely and operationally specific information, managerial ability to assimilate information)? Which of these determinants are especially important within an environment composed of many types of potential users facing information generated by a multifaceted publicprivate research sector?

(iii) Assessing Public-Private Roles in the Transfer of Research Produced Technologies. A plethora of public and private organizations sponsor technology transfer programs. Frequently cited in the literature are presumptions suggesting that each sector has a unique and responsible role. Are there conditions where but one sector embodies special attributes more important to effective transfer of certain technologies produced by research? What is the nature of these attributes (e.g., public: high-risk technologies; private: prior commercialization experience) and how might technology transfer responsibilities be allocated accordingly? Is there an advantageous blend of public-private sponsorship of technology transfer programs and how might such be ascertained and subsequently judged?

(iv) Evaluating the Efficiency and Effectiveness of Technology Transfer Programs. Programs engaged in the transfer of technologies are diverse in purpose, type, and size. Frequently cited in the literature is concern over their equally diverse efficiency and effectiveness. What is the fundamental intent of existing technology transfer programs (e.g., private programs: venture capital forms, angel investors, business incubators; public programs: extension, small business incentives, economic development) and how, and by what standards, might their performance be assessed? Based on the latter, are there opportunities for improving the effectiveness of these programs, including partnering to advance the attainment of common sector-wide interests in technology transfer? What role might special public or private incentives play in promoting technology transfer activities, and, if warranted, what might be their nature (e.g., tax incentives as commonly used promote research generally)? Might economies of scale be captured with adjustments in the size of technology transfer programs?

(v) Monitoring the Extent and Nature of Programs Involving the Transfer of Technologies. Organizations and programs engaged in technology transfer are cited in the literature as many in number and ever changing in their role and effectiveness. Periodic assessment of sector-wide conditions can provide a useful base from which to assess direction and intensity of the overall technology transfer enterprise. What public and private organizations and types of programs are currently engaged in the transfer of new technologies provided by research? What is the magnitude and focus of the investments made by these programs and are there discernable trends that should be of concern? What organizational 
and managerial challenges do leaders of technology transfer programs currently and prospectively face?

\section{Acknowledgments}

The paper was funded by the University of Minnesota's Department of Forest Resources and Minnesota Agricultural Experiment Station and by the Forest Products Laboratory, Forest Service, US Department of Agriculture. The constructive comments and suggestions of the paper's reviewers are greatly appreciated.

\section{References}

[1] P. V. Ellefson, M. A. Kilgore, K. E. Skog, and C. D. Risbrudt, "Wood utilization research and product development capacity in the United States: a review," Staff Paper Series Number 207, University of Minnesota, St. Paul, Minn, USA, 2010, http://www.forestry.umn.edu/Publications/index.htm.

[2] U.S. Government Accountability Office, "Wood utilization: federal research and development activities, support, and technology transfer," Tech. Rep. GAO-06-624, U.S. Government Accountability Office, Washington, DC, USA, 2006, http://www.gao.gov/new.items/d06624.pdf.

[3] P. V. Ellefson, M. A. Kilgore, K. E. Skog, and C. D. Risbrudt, "Technology transfer and knowledge utilization: a review of systems and organizations relevant to wood utilization research and product development in the United States," Staff Paper Series Number 208, University of Minnesota, St. Paul, Minn, USA, 2010, http://www.forestry.umn.edu/ Publications/index.htm.

[4] P. V. Ellefson and M. A. Kilgore, "United States woodbased industry: a review of structure and organization," Staff Paper Series Number 206, University of Minnesota, St. Paul, Minn, USA, 2010, http://www.forestry.umn.edu/ Publications/index.htm.

[5] National Capital Venture Association, Corporate Venture Capital Investment Analysis: 1995-2009, National Capital Venture Association, Arlington, Va, USA, 2010.

[6] S. Shane, The Importance of Angel Investing in Financing the Growth of Entrepreneurial Ventures, Office of Advocacy, U.S. Small Business Administration, Washington, DC, USA, 2008.

[7] S. J. Kline and N. Rosenberg, "An overview of innovation," in The Positive Sum Strategy, R. Landau and N. Rosenberg, Eds., p. 640, National Academy Press, Washington, DC, USA, 1986.

[8] AngelSoft Inc., AngelSoft: Early Stage Investment Group, AngelSoft Inc., New York, NY, USA, 2010.

[9] S. Maital, S. Ravid, D. V. R. Sesadri, and A. Dummanis, "Toward a grounded theory of effective business incubation," Vikalapa, vol. 33, no. 4, pp. 1-13, 2008.

[10] L. Knopp, State of the Business Incubation Industry: 2006, National Business Incubation Association, Athens, OH, USA, Catalog ID 396, 2007.

[11] O. Gassmann, "Towards a resource-based view of corporate incubators," International Journal of Innovation Management, vol. 10, no. 1, pp. 19-45, 2006.

[12] European Commission, "Benchmarking of business incubators," Center for Strategy and Evaluation Services, European Commission Enterprise Directorate General, European Commission, Brussels, Belgium.
[13] R. Landry, M. Lamari, and N. Amara, "The extent and determinants of the utilization of university research in government agencies," Public Administration Review, vol. 63, no. 2, pp. 192-205, 2003.

[14] National Business Incubator Association, Principles and Best Practices of Successful Business Incubation, National Business Incubator Association, Athens, Ohio, USA, 2010.

[15] A. Frenkel, D. Shefer, and M. Miller, "Public versus private technological incubator programmes: privatizing the technological incubators in Israel," European Planning Studies, vol. 16, no. 2, pp. 189-210, 2008.

[16] P. D. Cassidy, Cooperative Extension System Personnel in Forestry and Forest products, National Institute of Food and Agriculture, Washington, DC, USA, 2007.

[17] U.S. Small Business Administration, The Small Business Economy 2006: A Report to the President, U.S. Small Business Administration, Washington, DC, USA, 2007.

[18] U.S. Small Business Administration, SBA's Small Business Investment Program, U.S. Small Business Administration, Washington, DC, USA, 2010.

[19] National Governor's Association, "State strategies to promote angel investment for economic growth," Center for Best Practices, National Governor's Association, Washington, DC, USA, 2008, http://www.nga.org/cms/home.html.

[20] J. Williams, State Tax Credits and Government Incentives for Angel Investing, Belmont University, Nashville, Tenn, USA, 2008, Angel Capital Investment Foundation.

[21] Society of Wood Science and Technology, SWST Directory of North American Schools Offering Baccalaureate and Graduate Programs in Wood Science and Technology, Society of Wood Science and Technology, Monona, Wis, USA, 2010.

[22] A. N. Link and J. R. Link, Government as Entrepreneur, Lexington Books, Lexington, Mass, USA, 2009.

[23] R. Rich, "Measuring knowledge utilization process and outcomes," International Journal of Knowledge Transfer and Utilization, vol. 10, no. 3, pp. 3-10, 1997.

[24] C. H. Weiss, "The many meanings of research utilization," Public Administration Review, vol. 39, no. 5, pp. 426-431, 1997.

[25] C. Oh, "Science and politics: a view from an information utilization perspective," in Proceedings of the International Political Science Association World Congress, International Political Science Association, Quebec, Canada, 2000.

[26] O. Belkhodja, N. Amara, R. Landry, and M. Ouimet, "The extent and organizational determinants of research utilization in Canadian health services organizations," Science Communication, vol. 28, no. 3, pp. 377-417, 2007.

[27] J. Knott and A. Wildavsky, "If dissemination is the solution, what is the problem?" Knowledge: Creation, Diffusion, Utilization, vol. 1, no. 4, pp. 537-578, 1980.

[28] S. A. Zahra and G. George, "Absorptive capacity: a review, reconceptualization, and extension," Academy of Management Review, vol. 27, no. 2, pp. 185-203, 2002.

[29] M. J. Spilsbury and R. Nasi, "The interface of policy research and the policy development process: challenges posed to the forestry community," Forest Policy and Economics, vol. 8, no. 2, pp. 193-205, 2006.

[30] E. M. Rogers, Diffusion of Innovation, Free Press, New York, NY, USA, 1983.

[31] T. Boyle, V. Kumar, and U. Kumar, "Determinants of integrated product development diffusion," $R$ and $D$ Management, vol. 36 , no. 1 , pp. 37-54, 2006.

[32] D. Gerwin and N. J. Barrowman, "An evaluation of research on integrated product development," Management Science, vol. 48, no. 7, pp. 938-953, 2002. 
[33] E. J. Nijssen and R. T. Frambach, "Determinants of the adoption of new product development tools by industrial firms," Industrial Marketing Management, vol. 29, no. 2, pp. 121-131, 2000.

[34] J. Poolton and I. Barclay, "New product development from past research to future applications," Industrial Marketing Management, vol. 27, no. 3, pp. 197-212, 1998.

[35] P. V. Ellefson, M. A. Kilgore, K. E. Skog, and C. D. Risbrudt, "Forest products research and development organizations in a worldwide setting: a review of structure, governance, and measures of performance of organizations outside the United States," Tech. Rep. FPL-GTR-172, U.S. Department of Agriculture, Madison, Wiss, USA, 2007, http://www.fpl.fs.fed.us/index.php.

[36] D. Strelneck and P. Linquiyi, "Environmental technology transfer to developing countries: practical lessons learned during implementation of the Montreal Protocol," in Proceedings of the 7th Annual Research Conference, Association for Public Policy and Management, Fairfax, Va, USA, 1995.

[37] E. Bardach, Getting Agencies to Work Together: Practice and Theory, Brookings Institution Press, Washington, DC, USA, 1998.

[38] A. N. Link and L. L. Bauer, Cooperative Research in U.S. Manufacturing: Assessing Policy Initiatives and Corporate Strategies, Lexington Books, Lexington, MA, USA, 1989.

[39] National Research Council, Government-Industry Partnerships for the Development of New Technologies, National Academies Press, Washington, DC, USA, 2003.

[40] R. R. Cosner, "Industrial research institute's R\&D trends forecast for 2010," Research Technology Management, vol. 53, no. 1, pp. 14-22, 2010.

[41] Y. Baba, N. Shichijo, and S. R. Sedita, "How do collaborations with universities affect firms' innovative performance? The role of collaboration in the advanced materials field," Research Policy, vol. 38, no. 5, pp. 756-764, 2009.

[42] N. Radjou, "A network of innovation: new era of rapid innovation requires new approaches to R\&D," Strategic Direction, vol. 22, no. 10, pp. 39-41, 2006.

[43] National Aeronautics and Space Administration, "NASA license and patent program: Marshall Space Flight Center," National Space Flight Center, National Aeronautic and Space Administration, Huntsville, Ala, USA, 2010, http://techtran.msfc.nasa.gov/. 

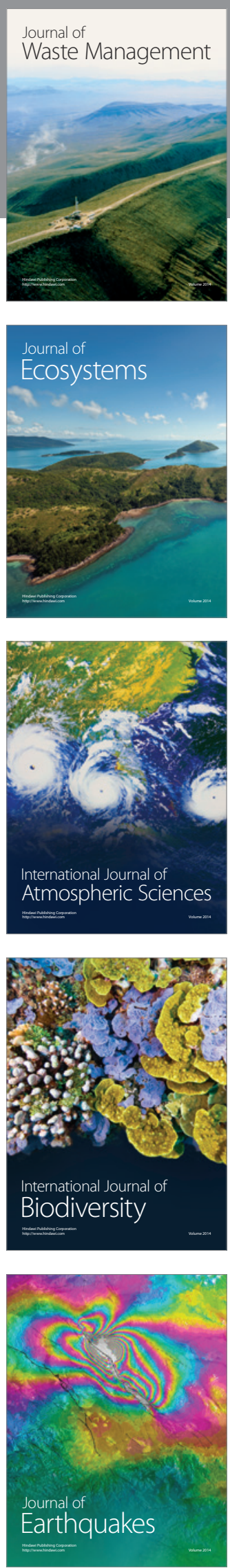
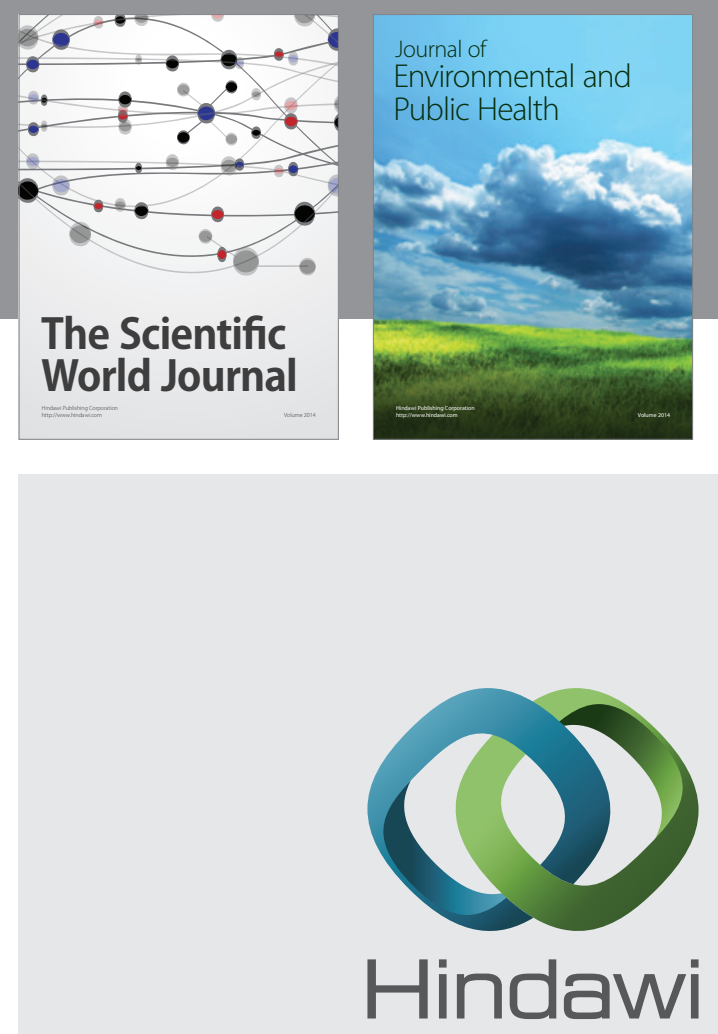

Submit your manuscripts at

http://www.hindawi.com
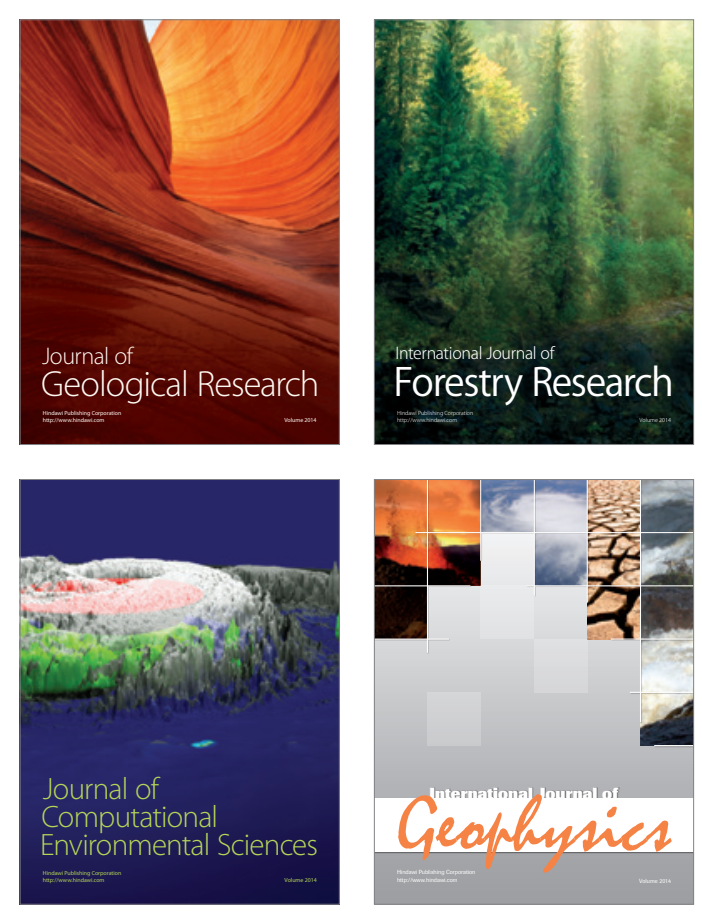
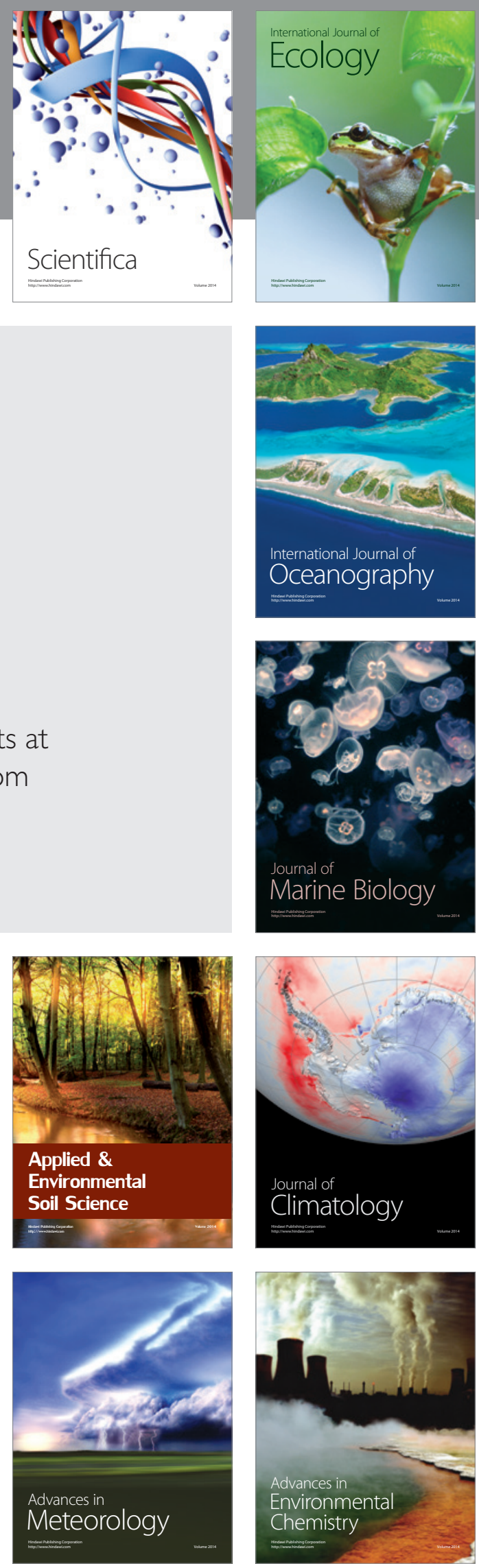